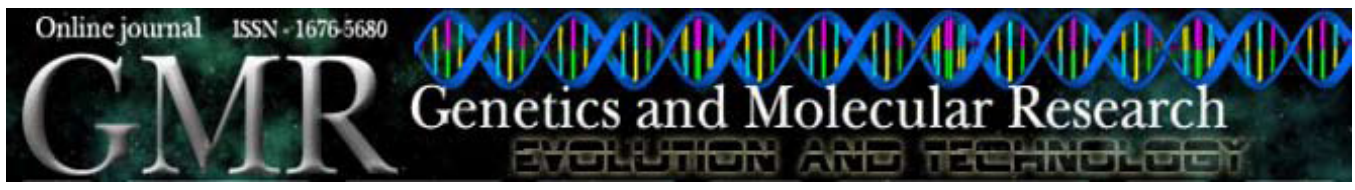

\title{
Leaf carbon assimilation and molecular phylogeny in Cattleya species (Orchidaceae)
}

\author{
V. Andrade-Souza, A.-A.F. Almeida, R.X. Corrêa, M.A. Costa, \\ M.S. Mielke and F.P. Gomes \\ Departamento de Ciências Biológicas, Universidade Estadual de Santa Cruz, \\ Ilhéus, BA, Brasil
}

Corresponding author: A.-A.F. Almeida

E-mail: alexalan@uesc.br

Genet. Mol. Res. 8 (3): 976-989 (2009)

Received March 28, 2009

Accepted June 6, 2009

Published August 11, 2009

\begin{abstract}
We examined leaf $\mathrm{CO}_{2}$ assimilation and how it varied among species within the orchid genus Cattleya. Measurements of $\mathrm{CO}_{2}$ assimilation and maximum quantum yield of PS II ( $\mathrm{Fv} / \mathrm{Fm})$ were made for mature leaves of nine species using a portable system for photosynthesis measurement and a portable fluorometer. Leaf area was measured with an area meter, and the specific leaf mass was determined. DNA of nine Cattleya species and two species of Hadrolaelia was extracted using the CTAB protocol. Each sample was amplified and sequenced using primers for the $\operatorname{trn} \mathrm{L}$ gene. The phylogenetic analyses, using neighborjoining and maximum parsimony methods, retrieved a group that included Cattleya and Hadrolaelia species, in which the unifoliate species were separated from the bifoliates. The topologies of the two cladograms showed some similarities. However, C. guttata (bifoliate) was placed in the unifoliate clade in the neighbor-joining tree, while $C$. warneri (unifoliate) was not placed in this clade in the maximum parsimony tree. Most Cattleya species keep the leaf stomata closed from 6 am to $4 \mathrm{pm}$. We suggest that $C$. elongata, $C$. tigrina and $C$. tenuis have $\mathrm{C}_{3}$-crassulacean acid metabolism since they open their stomata around $12 \mathrm{am}$. The $\mathrm{Fv} / \mathrm{Fm}$ values remained relatively constant during the measurements of $\mathrm{CO}_{2}$ assimilation. The same was observed for the specific leaf mass values, although great variations were found in the leaf area values. When the species were grouped using molecular data in the neighbor-joining
\end{abstract}


analysis, no relation was observed with $\mathrm{CO}_{2}$ assimilation.

Key words: Chloroplast gene; Crassulacean acid metabolism; Leaf gas exchange; Maximum quantum yield of PS II

\section{INTRODUCTION}

The genus Cattleya is one of the largest of the family Orchidaceae, and it is included in one of the largest subtribes, Laellinae, which is restricted to Neotropical America (van den Berg et al., 2000). Moreover, this genus comprises about 48 species, of which 30 occur in Brazil, and of these, 25 are endemic (van den Berg and Martins, 1998). These species occupy predominantly epiphytic habitats, and most show crassulacean acid metabolism (CAM). Additionally, they are of high ornamental value due to the size of their flowers, and many species are used for hybridization (van den Berg and Martins, 1998).

Cattleya species occur mainly in two distinct regions, forests throughout the Brazilian east coast and in the lower part of the humid declivities of the Andean Mountains in Peru, Colombia, Ecuador, and Venezuela, up to the southern part of Mexico. However, ecophysiological and genetic studies of epiphytic orchids of dense forest are scarce (Zotz and Hietz, 2001). Some studies of the genus Kalanchoe (Crassulaceae) indicate that the CAM species possess a strong genetic component, like the genera Aeonium and Sedum (Gehrig et al., 1997). Besides, there is a combination of genotypic, ontogenetic and environmental factors, such as light intensity, air relative humidity and water availability, under which physiologic and biochemical attributes of CAM are expressed (Cushman and Borland, 2002). Therefore, studies that relate photosynthetic and phylogenetic aspects of these species are of great importance.

Several classification systems exist for Cattleya, which include only four of the Brazilian species. Notwithstanding, the classification of Withner (1988) is the most accepted and mentioned in scientific works (van den Berg C, unpublished data). The genus Cattleya is polyphyletic, but there are two main sister clades, one includes the unifoliate species and the other the Brazilian bifoliate species (van den Berg et al., 2000). In Orchidaceae, the classifications based on morphological data, such as number of polyneas, is very common (D'Emerico et al., 2000). However, phylogenetic hypotheses based on morphological parameters have been questioned. More recent studies are based on genetic information, using molecular markers and specific genes. The chloroplast genome shows some advantages, such as little variation in size, unilateral inheritance and a high evolutionary rate. Additionally the use of this genome minimizes the risk of contamination of the orchid's DNA by fungus, since these plants live in association with these organisms (Cameron, 2004).

The chloroplastic region $\operatorname{trn} \mathrm{L}-\operatorname{trn} \mathrm{F}$ has been widely used in phylogenetic studies. The region encompasses the leonine tRNA, designated $\operatorname{trn} \mathrm{L}$. Moreover, it encloses the exon $\operatorname{trn} \mathrm{L} 5^{\prime}$ ' and the spacer between exon $\operatorname{trn} \mathrm{L}$ (UAA) 3' and $\operatorname{trn} \mathrm{F}$ (GAA) (Taberlet et al., 1991). This noncoding region shows high frequency of substitutions and is therefore useful in genetic analyses at the genus level (Gielly et al., 1996). Besides, it facilitates an intermediate level of resolution within Laellinae (Higgins et al., 2003).

Based on the works carried out with the family Bromeliaceae, it is believed that in this family CAM had evolved several times (Crayn et al., 2004), as well as in the Clusia genus (Clusiaceae). Gehrig et al. (2003) observed that the species of Clusia with this metabolism 
are distributed in distinct clades. However, they show that there is a direct relation between photosynthetic behavior and taxonomic distribution. This genus shows $\mathrm{C}_{3}$ metabolism, $\mathrm{C}_{3}-$ CAM and complete CAM, distributed in accordance with the taxonomic position. Therefore, it is believed that the CAM possesses a strong genotypic component (Gehrig et al., 2001).

Considering the strong genetic component of CAM, our hypothesis is that $\mathrm{CO}_{2}$ assimilation also follows this trend and varies among the species according to phylogenetic grouping. In the present study, we evaluated photosynthetic $\mathrm{CO}_{2}$ assimilation and its correlation with the genetic diversity in the genus Cattleya found in diverse ecosystems of the Atlantic Rain Forest of Bahia State, Brazil. The comparisons were based on a molecular phylogeny inferred from chloroplastic $t r n \mathrm{~L}$ intron sequences.

\section{MATERIAL AND METHODS}

\section{Genetic material and growth conditions}

Nine species of Cattleya (C. guttata Lindl., C. silvana Pabst, C. warneri T. Moore, $C$. kerrii Brieger and Bicalho, C. schilleriana Rchb.f., C. tenuis Campacci and Vedovello, C. tigrina A. Rich., C. aclandiae Lindl., and C. elongata Barb. Rodr.) from different ecosystems of the Atlantic Rain Forest of the State of Bahia, Brazil, and two species of the genus Hadrolaelia $(H$. grandis Lindley and Paxton - endemic to the southern part of the State of Bahia, and H. purpurata Lindl. and Paxton - occurring in the southern part of Brazil, in the States of São Paulo, Santa Catarina and Rio Grande do Sul) were collected in Ilhéus-BA and Blumenal-SC, respectively. These species were transplanted to perforated adobe vials filled with dry seeds of Spondias mombin L. (substratum) and maintained under greenhouse conditions at a mean temperature of $28 \pm$ $2^{\circ} \mathrm{C}$, relative humidity of $70 \pm 4 \%$ and $50 \%$ global radiation.

\section{Measurements of $\mathrm{CO}_{2}$ assimilation and maximum quantum yield of PS II (Fv/Fm)}

The $\mathrm{CO}_{2}$ assimilation $(A)$ measurements were carried out during diurnal and nocturnal cycles in the same mature leaf in three plants of each species, at regular intervals of $2 \mathrm{~h}$, using a portable system for measurements of photosynthesis (Li-Cor, Nebraska, USA), equipped with a source of artificial light 6400-02B RedBlue \#SI-925. During this period, the water vapor pressure deficit between the leaf and air (VPDL) and between air (VPDA) and leaf (LT) and air (AT) temperatures were also simultaneously recorded with the same equipment. In order to make the irradiance uniform during the measurements of $A$ in the diurnal cycle, due to the substantial cloudiness in the region, the photosynthetic photon flux density (PPFD) was fixed, taking into consideration the PPFD incident at the moment of the measurement. The minimum and maximum times for stabilization of the readings were 60 and $90 \mathrm{~s}$, respectively. The maximum coefficient of variation allowed to save each reading was $0.8 \%$.

The measurements of $\mathrm{Fv} / \mathrm{Fm}$ in leaf level were carried out during the diurnal cycle, also every $2 \mathrm{~h}$, in the same leaf and plants of the species used for the measurements of $A$, using a portable Opti-Sciences fluorometer (model OS-30p, USA). Prior to each measurement, a clip was placed on the leaf for $30 \mathrm{~min}$ before setting in motion the lights for measurement $(<0.1$ $\left.\mu \mathrm{mol} \cdot \mathrm{m}^{-2} \cdot \mathrm{s}^{-1}, \lambda>650 \mathrm{~nm}\right)$ and actinic light $\left(1600 \mu \mathrm{mol} \cdot \mathrm{m}^{-2} \cdot \mathrm{s}^{-1}\right)$, so that all the reaction centers acquired the oxidized condition. 


\section{Measurement of leaf area and determination of the specific leaf mass}

The mean values of leaf area (LA) for the species studied were obtained using an automatic meter of LA (Li-3100, Li-Cor, Nebraska, USA). Specific leaf mass (SLM) was calculated by the quotient between the leaf dry mass and the individual LA. Leaf dry mass was obtained after drying the plant material at $75^{\circ} \mathrm{C}$ until a constant mass was reached.

\section{DNA sequencing and phylogenetic analyses}

DNA was extracted from leaf fresh tissue or from samples stored in a freezer at $-80^{\circ} \mathrm{C}$, using the CTAB method (Doyle and Doyle, 1990), modified by Corrêa et al. (1999). The intron of the gene $\operatorname{trn} \mathrm{L}$ (region between exon $\operatorname{trn} \mathrm{L} 5^{\prime}$ ' and 3'), that corresponds to the combination of primers $\operatorname{trnL}-\mathrm{c}$ (5' CGAAATCGGTAGACGCTACG 3') and d (5' GGGGATAGAGGGACTTGAAC 3'), was used because it is more efficient in amplification in several plant species (Taberlet et al., 1991). Amplification was carried out in a GeneAmp ${ }^{\circledR}$ PCR System 9700 Applied Biosystems thermal cycler. The reaction conditions were 35 cycles, with $60 \mathrm{~s}$ at $94^{\circ} \mathrm{C}, 60 \mathrm{~s}$ at $53^{\circ} \mathrm{C}$, and $120 \mathrm{~s}$ at $72^{\circ} \mathrm{C}$.

Before sequencing, the polymerase chain reaction (PCR) products were enzymatically purified, using exonuclease I and alkaline phosphatase (Shrimp Alkaline Phosphatase, Amersham) following manufacturer instructions. PCR products were sequenced using the DYEnamic ${ }^{\mathrm{TM}}$ ET Terminator Sequencing kit $\left(\mathrm{MegaBace}^{\mathrm{TM}}\right)$ (Amersham Pharmacia Biotech, Inc.), following the protocols provided by the manufacturer, and analyzed in a MegaBACE automated DNA sequencer (Amersham and Life Science).

The alignment of the DNA sequences was performed using Clustal W implemented in the BioEdit program (Hall, 1999), followed by manual adjustments. Each sequence resulted from the previous comparison of six sequence repeats obtained for each species. The sequence alignments were converted into a nexus format matrix and analyzed using the MEGA program (Molecular Evolutionary Genetics Analysis), version 1.02 (Kumar et al., 2004).

Unweighted maximum parsimony analysis was performed using the WinClada program (Nixon, 2002) by means of a heuristical search, with 100 replications, initiating with five trees for replications, and neighbor joining analysis using Jukes-Cantor distance was performed in the MEGA 3.1. program (Kumar et al., 2004).

Two species of the genus Hadrolaelia (H. grandis and H. purpurata) along with other genera and species, namely Encyclia candollei Lindl., Epidendrum conopseum R. Brown, Laelia anceps Lindl., L. autumnalis Lindl. and L. speciosa (Kunth) Schltr. were included as outgroup. The outgroup GenBank accession numbers are AY422423, AY422383, AF267021, AF267019, and AF267018, respectively.

\section{Statistical analysis}

The plants were arranged in a complete randomized design with nine treatments and three replications. Analyses of variance were carried out using the procedure of the SPSS ${ }^{\circledast}$ statistical program (1999). Mean rankings were done using the Tukey test $(\mathrm{P}<0.05)$ for each time of evaluation. 


\section{RESULTS}

\section{Leaf carbon assimilation}

In order to evaluate and to compare $\mathrm{CO}_{2}$ assimilation between the species of Cattleya studied, they were arranged following the groupings formed by neighbor joining analysis. There were no great variations in the mean values of the microclimatic variables, during the diurnal and nocturnal courses of gas exchange measurements. The largest values of PPFD, LT, AT, VPDL, and VPDA were approximately $1000 \mu \mathrm{moL}$ photons $\cdot \mathrm{m}^{-2} \cdot \mathrm{s}^{-1}$, $37^{\circ}, 38^{\circ} \mathrm{C}, 3.8$ and $4.0 \mathrm{kPa}$, respectively, recorded at $12 \mathrm{am}$. On the other hand, the smallest values of LT, AT, VPDL, and VPDA were approximately $26^{\circ}, 27^{\circ} \mathrm{C}, 0.9$ and $1.1 \mathrm{kPa}$, respectively, recorded at $10 \mathrm{pm}$ (Figure 1).

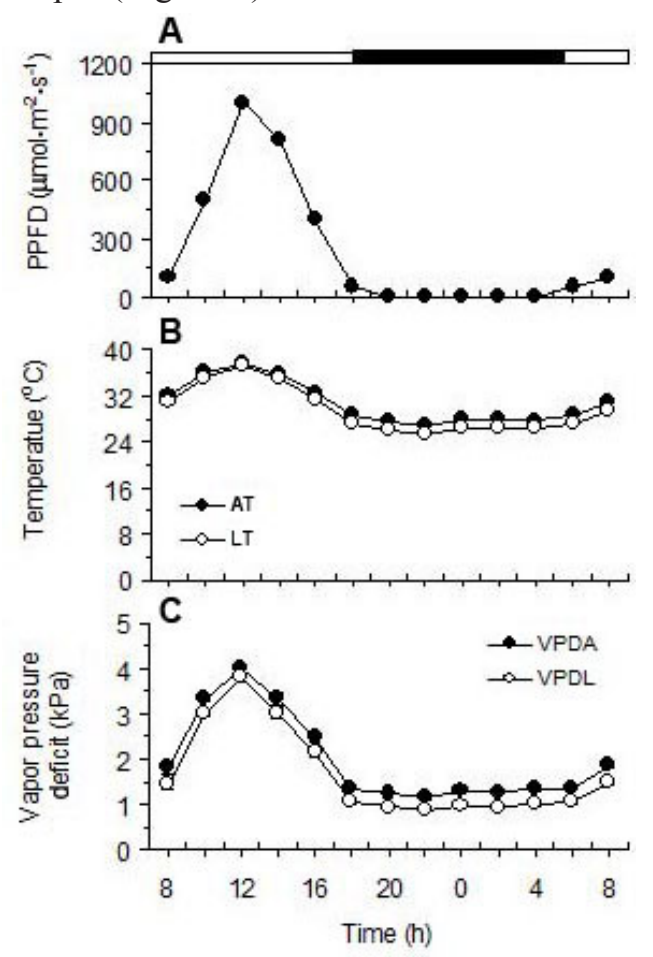

Figure 1. Photosynthetic photon flux density (PPFD) fixed during the measurements of $\mathrm{CO}_{2}$ assimilation (A), mean values of leaf (LT) and air (AT) temperatures (B) and water vapor pressure deficit between the leaf and air (VPDL) and of air (VPDA) (C) recorded during the diurnal and nocturnal cycles. Each point represents the mean \pm SE value of 27 replications. The full horizontal bar indicates the night cycle.

The maximum peaks of $\mathrm{CO}_{2}$ assimilation $(A)$ for the species $C$. guttata, C. silvana, C. waneri, C. kerrii, C. schilleriana, C. tenuis, C. tigrina, C. aclandiae, and C. elongata were approximately $6,4,6,8,3,6,2.5,4$, and $6 \mu \mathrm{moL} \mathrm{CO} \cdot \mathrm{m}^{-2} \cdot \mathrm{s}^{-1}$, occurring at $4 \mathrm{am}, 8 \mathrm{pm}, 6-12$ pm, $10 \mathrm{pm}, 2$ am, 10, 6, 12, and 8 pm, respectively (Figure 2A-C). 

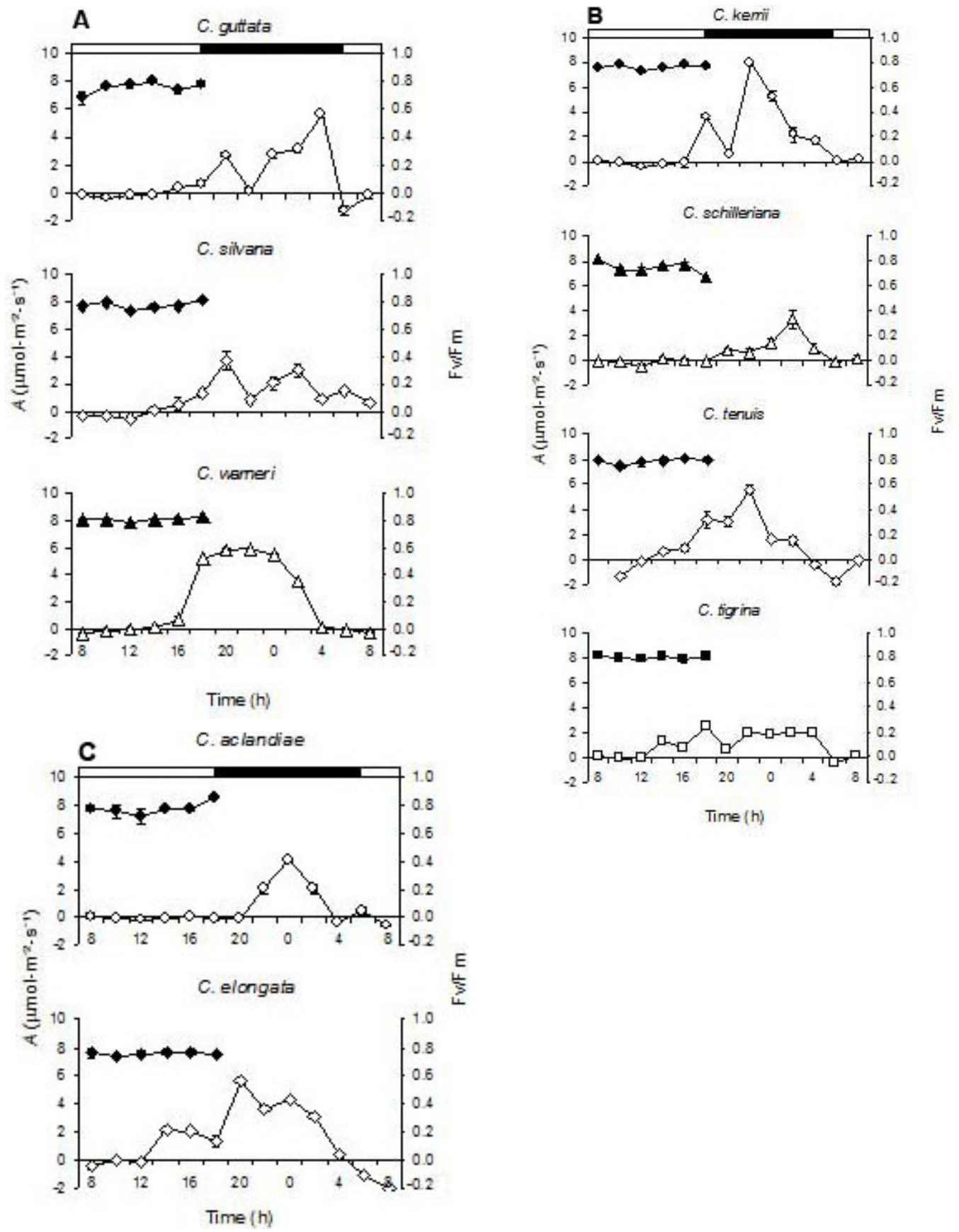

Figure 2. Mean values of $\mathrm{CO}_{2}$ assimilation $(A)$ (open symbol) and maximum quantum yield of PS II (Fv/Fm) (closed symbol) of A. Cattleya guttata, C. silvana and C. warneri; B. C. kerrii, C. schilleriana, C. tenuis, and C. tigrina; C. C. aclandiae and C. elongata. Each point represents the mean $\pm \mathrm{SE}$ value of three replications. The full horizontal bar indicates the night cycle. 
The species $C$. guttata, C. silvana, C. warneri and C. kerrii opened their stomata starting at $4 \mathrm{pm}$ (Figure 2A,B). However, for the C. tenuis, C. tigrina and C. elongata, this aperture occurred starting at 12 am (Figure 2B,C). In the first two species, the stomata remained open for approximately 18 and $16 \mathrm{~h}$, respectively. The last was one of the species whose stomata remained open the longest time, with certain oscillations during this period (Figure 2C). The species C. tigrina exhibited a longer time of stomatal aperture, although it showed a smaller $\mathrm{CO}_{2}$ assimilation rate, together with to C. schilleriana (Figure 2B). In the case of the C. aclandiae, the stomatal aperture only happened in the period of darkness (Figure 2C). C. silvana also displayed a curve similar to that of $C$. tigrina, but $\mathrm{CO}_{2}$ assimilation started at $4 \mathrm{pm}$ and continued until 8 am of the following day (Figure 2A). However, for $C$. warneri the stomata opened at $4 \mathrm{pm}$ and closed at 4 am. During this period, $\mathrm{CO}_{2}$ assimilation was practically constant from $6 \mathrm{pm}$ to $12 \mathrm{pm}$ forming a plateau. Possibly, it is the species that assimilated the greatest amount of $\mathrm{CO}_{2}$ (Figure 2A). On the other hand, C. kerrii showed the highest peak of $\mathrm{CO}_{2}$ assimilation $\left(7.96 \mu \mathrm{moL} \cdot \mathrm{m}^{-2} \cdot \mathrm{s}^{-1}\right)$, but there was a small peak $\left(3.53 \mu \mathrm{mol} \cdot \mathrm{m}^{-2} \cdot \mathrm{s}^{-1}\right)$ observed at about $6 \mathrm{pm}$ (Figure 2B).

In relation to the ratio $\mathrm{Fv} / \mathrm{Fm}$, the species $C$. aclandiae and $C$. schilleriana showed constant values during the diurnal cycle, except at $6 \mathrm{pm}$ when there was an increase in $\mathrm{Fv} / \mathrm{Fm}$ for $C$. aclandiae and a decrease for C. schilleriana $(\mathrm{P}<0.05)$ (Figure 2B,C). The constancy of $\mathrm{Fv} / \mathrm{Fm}$ values was also observed for C. silvana, C. guttata, C. warneri, C. tenuis, and C. tigri$n a$, which differed in relation to the level of $\mathrm{CO}_{2}$ assimilation; although there was coincidence with the time of stomata opening. The stomata of $C$. tigrina and C. tenuis opened at $12 \mathrm{am}$.

There was a great range of the LA values among the species of Cattleya. The smallest and largest values were $0.1 \times 10^{-2}$ and $1.5 \times 10^{-2} / \mathrm{m}^{2}$ for C. aclandiae and C. warneri, respectively (Figure 3). On the other hand, the SLM did not show large variation among the species, whose values ranged from 2.08 to $2.35 \times 10^{2} \mathrm{~g} / \mathrm{m}^{2}$ for C. kerrii and C. schilleriana, respectively (Figure 3).

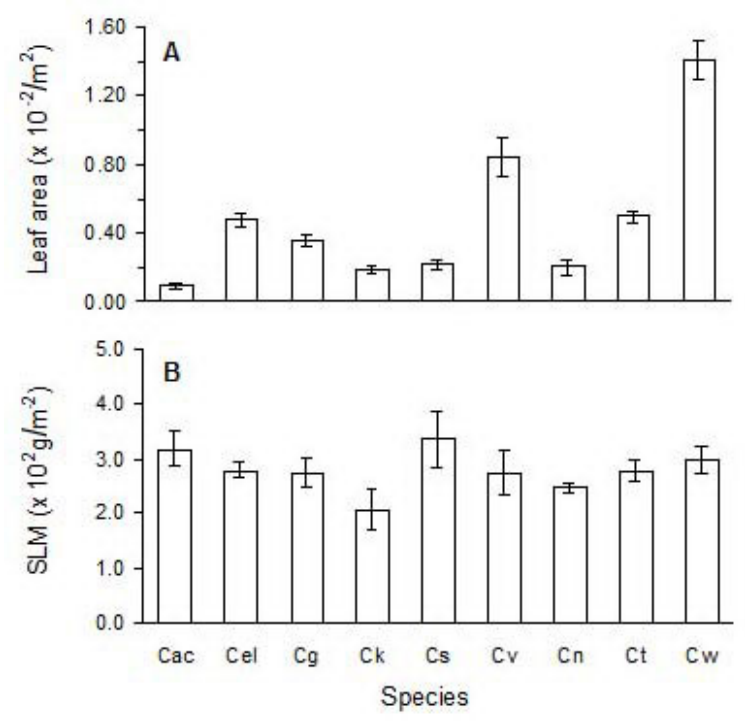

Figure 3. Individual leaf area (A) and specific leaf mass (SLM; B) of Cattleya aclandiae (Cac), C. elongata (Cel), C. guttata $(\mathrm{Cg})$, C. kerrii $(\mathrm{Ck})$, C. schilleriana $(\mathrm{Cs})$, C. silvana $(\mathrm{Cv})$, C. tenuis $(\mathrm{Cn})$, C. tigrina $(\mathrm{Ct})$, and $C$. warneri $(\mathrm{Cw})$. Each bar represents the mean $\pm \mathrm{SE}$ value of three to five replications. 


\section{Phylogenetic analysis}

The size of the fragment sequenced varied among the species (from 408 to $490 \mathrm{bp}$ ), as a consequence of the occurrence of some deletions and/or insertions, resulting in the inference of several gaps during the alignment of the sequences of the 16 species. From the alignment, a data matrix of 504 characters was generated. Each base position was treated as a character having up to four states represented by the nitrogenous bases of DNA. Fifty-one of the 504 sites obtained from the aligned sequences, were informative for the parsimony analysis $(10.12 \%)$.

The uncorrected pairwise sequence divergence was low, varying between 0.2 and $5 \%$ in the taxa studied. The smallest values were observed between E. condollei and L. speciosa and between $L$. automnalis and L. anceps, while the largest value was found between $H$. purpurata and C. warneri. Therefore, the Cattleya species showed intermediate levels of variation. In the analysis of the base composition of each species, a high $\mathrm{A}$ and $\mathrm{T}$ base content was observed, corresponding to $68 \%$, with little variation in the species analyzed.

\section{Neighbor joining analysis}

Neighbor joining was used to obtain a phylogenetic tree in which the species of Cattleya were grouped with Hadrolaelia. However, the group formed by C. aclandiae + C. elongata was positioned as sister group of the clade that contains the other species of Cattleya + Hadrolaelia (Figure 4). The grouping of $C$. aclandiae (epiphytic) with C. elongata (rupicolous) diverges from the morphological data and from the previous molecular analyses.

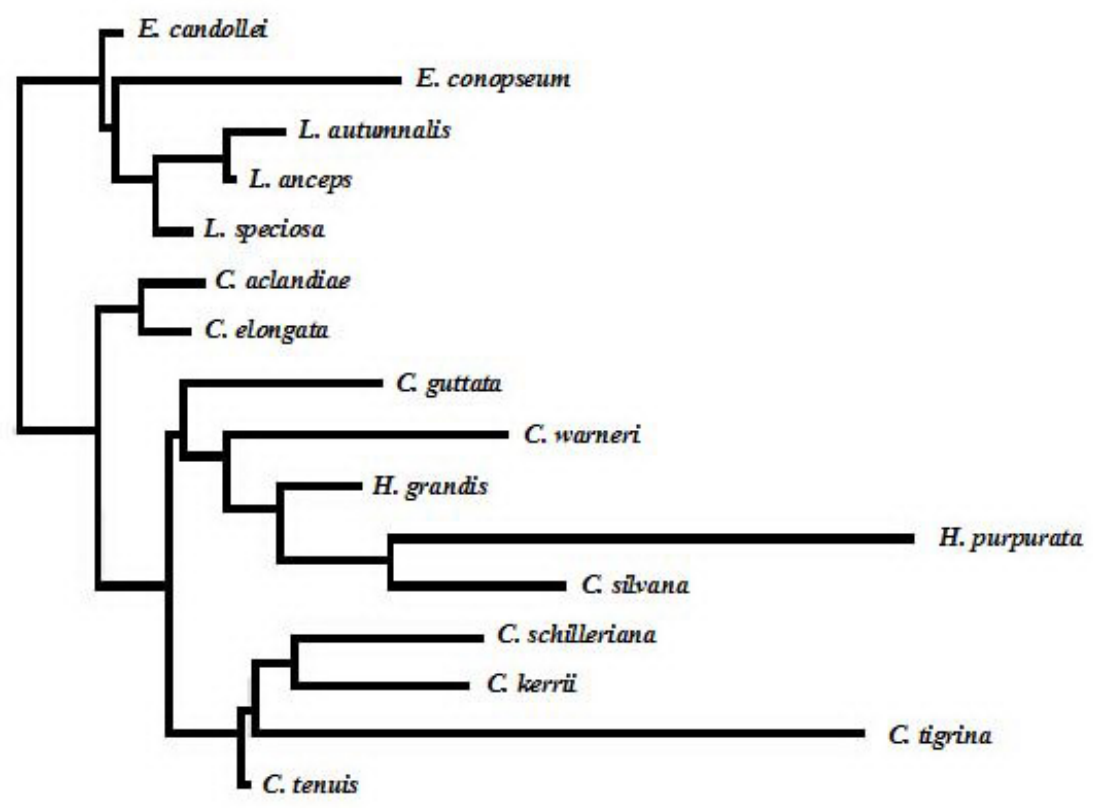

Figure 4. Neighbor joining tree obtained from sequences of the intron trnL. 
In a larger clade, there was the formation of two groups. The first, congregates the majority of the bifoliate Cattleya, excluding $C$. guttata, which was positioned basally to the second group, composed of the unifoliate species $C$. warneri, $H$. grandis and $C$. silvana $+H$. purpurata. In the first group, $C$. tenuis appears as sister group to the species $C$. tigrina and $C$. schilleriana + C. kerrii (Figure 4).

\section{Maximum parsimony method}

Maximum parsimony analysis resulted in four most parsimonious trees of 78 steps. A strict consensus tree is shown in the Figure 5. The consistency and retention indices were 0.79 and 0.68 , respectively.

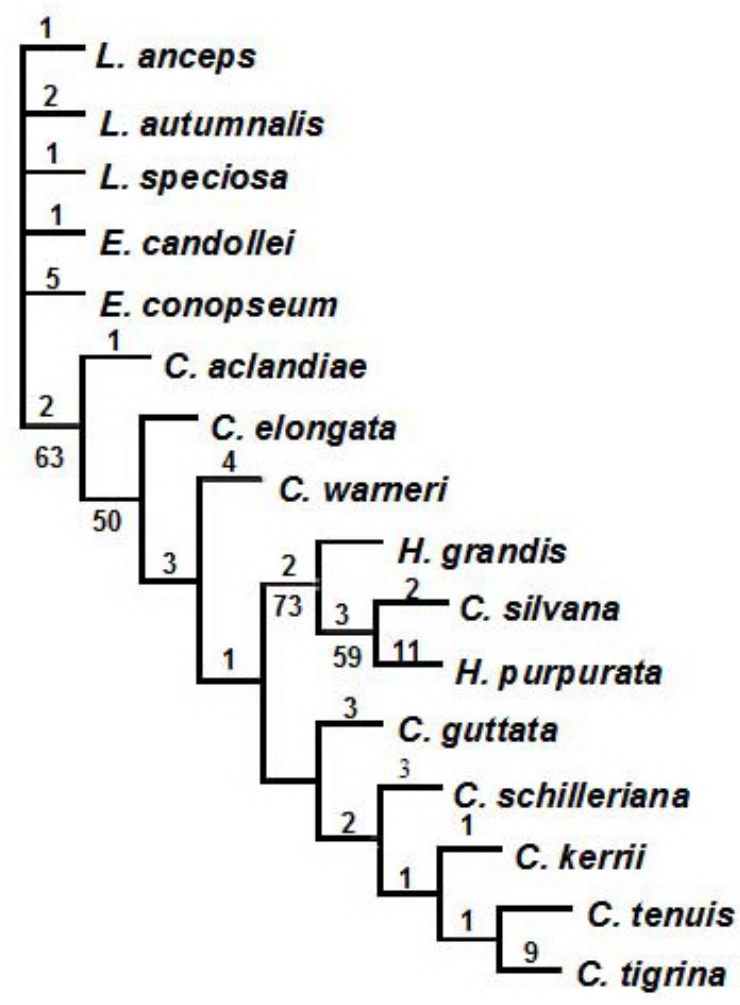

Figure 5. Strict consensus tree obtained from the four most parsimonious trees from intron $\operatorname{trn} \mathrm{L}$ sequence analyses. The numbers above the branches represent the number of changes that occurred on the branch and the numbers below correspond to the bootstrap proportions. Length $=78$, consistency index $=0.79$ and retention index $=0.68$.

In general, the bootstrap values were low. However, the largest supports were obtained for the clade that contains all species of Cattleya. The species C. aclandiae and $C$. elongata were positioned basally to that clade. This fact was also observed in grouping by neighbor joining. $C$. warneri was placed basally as sister group of a clade containing species 
of Hadrolaelia + Cattleya. The clade including species of Hadrolaelia and C. silvana found in the neighbor joining analysis was recovered in the parsimony analysis. However $C$. guttata was placed as sister group of $C$. schilleriana, $C$. kerrii and $C$. tenuis $+C$. tigrina, and $C$. warneri was located separate from the unifoliate species. The grouping of the species $C$. schilleriana, C. kerrii and C. tenuis + C. tigrina was similar to that with neighbor joining, although with some different arrangements.

\section{DISCUSSION}

Interspecific differences were observed in relation to leaf $\mathrm{CO}_{2}$ assimilation, taking into account the variation in stomatal opening and $\mathrm{CO}_{2}$ assimilation peaks (Figure 2A-C). The CAM orchids, such as Phalaenopsis grandifolia, Dendrobium crumenatum and Vanda sp, show maximum $A$ values of $0.5,1.8$ and $2.2 \mu \mathrm{mol} \mathrm{CO} \cdot \mathrm{m}^{-2} \cdot \mathrm{s}^{-1}$ (Goh and Kluge, 1989), respectively, at night. In general, these $A$ values are lower than those obtained in this study for the species of Cattleya of different ecosystems of Atlantic Rain Forest in the Bahia State, Brazil.

Stomata open or close in response to many environmental factors, such as light (amount, duration, quality), humidity, $\mathrm{CO}_{2}$ concentration, and atmospheric pollution. Although changes in aperture do not occur instantaneously, they can take place within just a few minutes, rapidly enough for the leaf to adjust its gas exchange to accommodate commonplace changes in the environment (e.g., sudden increases in wind speed or a change from cloudy to sunny conditions) that could impose severe stress (Jones, 1998). Such rapid adjustments are needed because the leaves' water reserves are small compared to the potential rate of transpiration.

In agreement with Adelberg et al. (1998) the species of Cattleya, as well as the majority of epiphytes, use CAM. Usually, CAM plants conserve water, restricting the stomatal opening and $\mathrm{CO}_{2}$ absorption during the night, when the temperature of the air and water vapor pressure deficit of air are low in relation to the diurnal period (Kluge and Ting, 1978). In contrast to what was seen in the present study with the species $C$. elongata, $C$. tenuis and C. tigrina, stomata opened at about $12 \mathrm{am}$ and stayed open at night. The fact that $C$. elongata opened stomata earlier and also remained open longer with certain oscillations during this period (Figure 2C) was expected, due to the habit of rupicolous growth and because it is a species adapted to the conditions of full sunlight in the region of the Chapada Diamantina, BA, Brazil (about $1000 \mathrm{~m}$ above the sea level). Moreover, the leaves of this species show high concentrations of anthocyanins, pigments that have a photoprotective role (Close and Beadle, 2003). On the other hand, $\mathrm{CO}_{2}$ assimilation for the species C. aclandiae and C. elongata was very different, although they are in the same grouping (Figure 2C).

The species $C$. elongata, $C$. tenuis and $C$. tigrina probably show facultative $\mathrm{C}_{3}$-CAM for $\mathrm{CO}_{2}$ assimilation. Species that display this intermediate mechanism use $\mathrm{C}_{3}$ metabolism to maximize growth, when in conditions of good water availability to assimilate greater amounts of $\mathrm{CO}_{2}$; it also makes it possible, under conditions of water deficiency, to maintain photosynthetic integrity (Cushman, 2001). Environmental factors such as relative humidity, air temperature and light intensity can also influence that transition (Franco et al., 1999). However, it would be necessary to study light saturation curves, together with the determination of the concentration of the organic acid (malate or aspartate) involved in the assimilation of $\mathrm{CO}_{2}$, to really prove this hypothesis.

The internal concentration of $\mathrm{CO}_{2}\left(\rho^{\mathrm{I}} \mathrm{CO}_{2}\right)$ during phase III of $\mathrm{CO}_{2}$ assimilation in CAM plants, can correspond to $0.15 \%$ in relation to $\mathrm{CO}_{2}$ atmospheric concentration for the genus Cat- 
tleya. This process proceeds with the stomata remaining closed during the day, because $\rho^{\mathrm{I}} \mathrm{CO}_{2}$ has an important role in the regulation of the stomatal aperture (Lüttge, 2004). However, this concentration can vary among the species of Cattleya, which might have caused the variation in the hours of stomatal opening of the species analyzed. Besides, the four phases of metabolism of the CAM type, in spite of being well described for some species such as Kalanchoe daigremontiana, do not constitute a rigid division of the theoretical and practical points of view, mainly because of showing wide plasticity among the species and because they are related to environmental variations (light, temperature, water availability, and others) (Dodd et al., 2002).

The constancy in Fv/Fm values during the diurnal course implies that the plants of the different species of orchids studied did not suffer any type of environmental stress that could affect the $\mathrm{CO}_{2}$ assimilation rate. Besides, it demonstrates that there was an efficient use of the absorbed energy and that chlorophyll was capable of transferring the excitation energy for the reaction centers of PS II (Almeida and Maestri, 1996). According to Jeon et al. (2006), differences in $\mathrm{CO}_{2}$ assimilation in CAM-type species are related to environmental factors such as air temperature. However, this was not observed in that study, because $\mathrm{Fv} / \mathrm{Fm}$ values displayed little variation and also the temperature of the air was practically the same for all species studied during the evaluation of leaf gas exchange.

There was a great discrepancy in relation to the values of individual LA. However, SLM values did not show great interspecific variations (Figure 3). Therefore, it can be inferred that relatively constant values of SLM demonstrate the existence of proportionality in relation to leaf biomass and LA, indicating that reduction in LA was compensated by increase in leaf thickness. Differences in leaf thickness could cause morpho-physiological variations, implicated in alterations in the diffusive resistance to $\mathrm{CO}_{2}$, as well as in the content of photosynthetic pigments, carboxylating enzymes, among others (Silva et al., 2001). According to Stuntz and Zotz (2001), high values of net photosynthetic rate in epiphytic orchids are associated with low values of specific leaf area, which implies high values of SLM.

Regarding the molecular data used in the phylogenetic analysis, it was shown that the size of the fragment was similar to that found previously in several angiosperm species for the intron trnL (Taberlet et al., 1991). However, the size used in the present analysis varied among the species. One of the reasons for that variation was due to low efficiency of the sequencing in the beginning and at the end of the fragment, leading to the exclusion of ambiguous bases to the point where the sequences exhibited greater robustness between the species.

The rate of $10.12 \%$ of informative sites was relatively low, although it is close to that found for the genus Encyclia (Orchidaceae) (12.7\%), even considering the intergenic spacer (Higgins et al., 2003). Such low rate was also observed for Korthalsella in the same region of the intron (11.1\%) and in the region of the intergenic spacer (13.7\%; Molvray et al., 1999). In some previous studies, higher rates were obtained using the same intron $(25 \%)$ (Muasya et al., 2002) or the intron + spacer trnL-F (18.6\%; Chase et al., 2000) and (37.5\%; Kores et al., 2001). The variation between 0.2 and $5 \%$ obtained by the p-distance was also similar to that reported for Korthalsella (Molvray et al., 1999). The high content of $\mathrm{A}$ and $\mathrm{T}$ bases in the cpDNA could reduce its potential in phylogenetic studies, among higher taxonomic levels. However, those regions can be considered useful in studies involving close taxonomic groups (Gielly and Taberlet, 1994).

In studies conducted by Gielly and Taberlet (1994), in which the intron trn L and the intergenic spacer $\operatorname{trn} \mathrm{L}-\operatorname{trn} \mathrm{F}$ were used, comparison with data of another chloroplastidic ( $\mathrm{rbcL}$ ) 
gene indicated that the noncoding regions develop faster, showing insertions and deletions. These same authors believed that the introns developed at a lower rate in relation to the intergenic spacer, mainly due to the secondary structure and the catalytic properties of the intron.

With the aim of evaluating leaf carbon assimilation under the phylogenetic relationships in the genus Cattleya, the species were arranged taking into account the groupings formed in the cladogram obtained by the neighbor joining method. The groupings obtained with this method diverge from some morphological findings and previous molecular data, such as for C. aclandiae (epiphytic), which was positioned with C. elongata (rupicolous), where flowers and other characteristics are very differentiated, for example, the height of the plants reaching about 22 and $75 \mathrm{~cm}$, respectively. On the other hand, in the analyses with internal transcribed spacer (ITS), these two species were separated into different groups (van den Berg et al., 2000) and, according to the classification of Withner (1988), they belong to distinct subgenera (Aclandia and Schomburgkoidea, respectively).

The classification proposed by Withner (1988), based on morphological characters, shows incongruence in relation to the positioning of $C$. tenuis, which appears as sister group of the species C. tigrina and C. schilleriana $+C$. kerrii (Figure 4), placing C. tenuis, C. kerrii and C. schilleriana in different subgenera (Schomburgkoidea, Intermedia, and Falcata, respectively). Although differing from the traditional morphological analyses, the present results reinforce previous molecular propositions including larger number of species that indicated a closer proximity between $C$. kerrii and $C$. schilleriana and between $C$. tenuis and C. tigrina (van den Berg et al., 2000).

In relation to the second group, the inclusion of $H$. purpurata and $H$. grandis in the same group of Cattleya was suggested by van den Berg et al. (2000), based on the analyses of ITS sequences. In that analysis, the Laelia genus was divided into two groups, one formed by Mexican Laelia and other by Brazilian Laelia, including L. purpurata and L. grandis, grouped with species of Cattleya. Later, Brazilian Laelia were included by Chiron and Castro Neto (2002) in a new genus, denominated Hadrolaelia. L. purpurata and L. grandis were further denominated $H$. purpurata and $H$. grandis. $C$. silvana, positioned in this clade with Hadrolaelia, can be a natural hybrid between H. grandis and C. warneri, described in 1976 as Laeliocattleya albanensis (Menezes, 2005). On the other hand, Cruz et al. (2003) suggest that $C$. silvana is an intergeneric hybrid between C. warneri and Sophronitis, a synonym of Sophrocattleya albanensis. Considering these hypotheses and the results of the present analysis, more detailed studies are necessary, including a larger number of species and the discerning selection of taxa and new molecular characters, to explain the complex relationships inside this group.

The strict consensus tree, obtained by the method of the maximum parsimony, confirmed the grouping of the species of Cattleya (Figure 5), although with low bootstrap values. However, the greatest supports were obtained for the clade that contained all species of Cattleya. The basal grouping species $C$. aclandiae and C. elongata and the grouping of the species of Hadrolaelia and of C. silvana were also observed in neighbor joining analyses. The positioning of $C$. guttata in the group of the bifoliates is in agreement with what was proposed by the analyses with ITS sequences, which contains all bifoliate species (van den Berg et al., 2000). However, the basal positioning of $C$. warneri in this analysis separates this species from the unifoliates.

In general, the two analyses performed were solid, resulting in trees with relatively similar topologies, mainly in the separation of the unifoliate species from the bifoliates. How- 
ever, the positioning of $C$. guttata and $C$. warneri diverged. In the neighbor joining analysis, they were placed in the clade of the unifoliates, while using maximum parsimony they were positioned separate from the other unifoliates. On the other hand, the present results were shown to be informative for the phylogenetic reconstruction of the species of the Cattleya genus included, although the number of the taxa analyzed was small, compared with the number of existing species in the genus. Besides, the groupings obtained demonstrate consistency with previous molecular analyses and with some morphologic groups previously proposed. However, the inclusion of new species, as well as the use of other genes, will certainly allow the retrieval of more solid results concerning the phylogenetic relationships in this genus.

Additionally, according to the present analyses, we did not find a direct relationship between $\mathrm{CO}_{2}$ assimilation and the molecular phylogenetic data. The metabolism of the CAM type, although showing a strong genotypic component for some groups, also displays ample phenotypic plasticity. These facts are probably not associated directly with $\mathrm{CO}_{2}$ assimilation, which can be related to the effect of environmental variations, besides genetic aspects.

\section{ACKNOWLEDGMENTS}

Research supported by Fundação de Amparo à Pesquisa do Estado da Bahia (FAPESB) and by the Coordenação de Aperfeiçoamento de Pessoal de Nível Superior (CAPES). We thank João Eduardo dos Santos for furnishing the specimens. A.-A.F. Almeida gratefully acknowledges the Conselho Nacional de Desenvolvimento Científico e Tecnológico (CNPq), Brazil, for the concession of a fellowship of scientific productivity.

\section{REFERENCES}

Adelberg J, Pollock R, Rajapakse N and Young R (1998). Micropropagation, decontamination, transcontinental shipping and hydroponic growth of Cattleya while sealed in semipermeable membrane vessels. Sci. Hortic. 73: 23-35.

Almeida AAF and Maestri M (1996). Characteristics of slow chlorophyll fluorescence emission in four Coffea arabica genotypes submitted to water stress. Photosynthetica 32: 161-169.

Cameron KM (2004). Utility of plastid psaB gene sequences for investigating intrafamilial relationships within Orchidaceae. Mol. Phylogenet. Evol. 31: 1157-1180.

Chase MW, Bruijn AY, Cox AV, Reeves G, et al. (2000). Phylogenetics of Asphodelaceae (Asparagales): an analysis of plastid $r b c L$ and trnL-F DNA sequences. Ann. Bot. 86: 935-951.

Chiron GR and Castro Neto VP (2002). Revision des espèces brésiliennes du genre Laelia Lindley. Richardiana 2: 14-28.

Close DC and Beadle CL (2003). The ecophysiology of foliar anthocyanin. Bot. Rev. 69: 149-161.

Corrêa RX, Abdelnoor RV, Faleiro FG, Cruz CD, et al. (1999). Genetic distances in soybean based on RAPD markers. Bragantia 58: 15-22.

Crayn DM, Winter K and Smith JA (2004). Multiple origins of crassulacean acid metabolism and the epiphytic habit in the Neotropical family Bromeliaceae. Proc. Natl. Acad. Sci. U. S. A. 101: 3703-3708.

Cruz DT, Borba EL and van den Berg C (2003). O gênero Cattleya Lindl. (Orchidaceae) no estado da Bahia, Brasil. Sitientibus Ser. Cienc. Biol. 3: 26-34.

Cushman JC (2001). Crassulacean acid metabolism. A plastic photosynthetic adaptation to arid environments. Plant Physiol. 127: 1439-1448.

Cushman JC and Borland AM (2002). Induction of crassulacean acid metabolism by water limitation. Plant Cell Environ. 25: 295-310.

D’Emerico S, Pignone D and Scrugli A (2000). Giemsa C-banded karyotypes in Serapias L. (Orchidaceae). Bot. J. Linn. Soc. 133: 485-492.

Dodd AN, Borland AM, Haslam RP, Griffiths H, et al. (2002). Crassulacean acid metabolism: plastic, fantastic. J. Exp. Bot. 53: 569-580. 
Doyle JJT and Doyle JL (1990). Isolation of plant DNA from fresh tissue. Focus 12: 13-15.

Franco AC, Herzog B, Hubner C, De Mattos EA, et al. (1999). Diurnal changes in chlorophyll a fluorescence, $\mathrm{CO}_{2}-$ exchange and organic acid decarboxylation in the tropical CAM tree Clusia hilariana. Tree Physiol. 19: 635-644.

Gehrig HH, Rösicke H and Kluge M (1997). Detection of DNA polymorphisms in the genus Kalanchoë by RAPD-PCR fingerprint and its relationships to infrageneric taxonomic position and ecophysiological photosynthetic behaviour of the species. Plant Sci. 125: 41-51.

Gehrig HH, Gaussmann O, Marx H, Schwarzott D, et al. (2001). Molecular phylogeny of the genus Kalanchoë (Crassulaceae) inferred from nucleotide sequences of the ITS-1 and ITS-2 regions. Plant Sci. 160: 827-835.

Gehrig HH, Aranda J, Cushman MA, Virgo A, et al. (2003). Cladogram of Panamanian Clusia based on nuclear DNA: implications for the origins of crassulacean acid metabolism. Plant Biol. 5: 59-70.

Gielly L and Taberlet P (1994). The use of chloroplast DNA to resolve plant phylogenies: noncoding versus rbcL sequences. Mol. Biol. Evol. 11: 769-777.

Gielly L, Yuan YM, Kupfer P and Taberlet P (1996). Phylogenetic use of noncoding regions in the genus Gentiana L.: chloroplast trnL (UAA) intron versus nuclear ribosomal internal transcribed spacer sequences. Mol. Phylogenet. Evol. 5: 460-466.

Goh CJ and Kluge M (1989). Gas Exchange and Water Relations in Epiphytic Orchids. In: Vascular Plants as Epiphytes: Evolution and Ecophysiology (Lüttge U, ed.). Springer-Verlag, Berlin, 139-166.

Hall TA (1999). BioEdit: a user-friendly biological sequence alignment editor and analysis program for Windows 95/98/ NT. Nucleic Acids Symp. Ser. 41: 95-98.

Higgins WE, van den Berg C and Whitten WM (2003). A combined molecular phylogeny of Encyclia (Orchidaceae) and relationships within Laeliinae. Selbyana 24: 165-179.

Jeon MW, Ali MB, Hahn EJ and Paek KY (2006). Photosynthetic pigments, morphology and leaf gas exchange during ex vitro acclimatization of micropropagated CAM Doritaenopsis plantlets under relative humidity and air temperature. Environ. Exp. Bot. 55: 183-194.

Jones HG (1998). Stomatal control of photosynthesis and transpiration. J. Exp. Bot. 49: 387-398.

Kluge M and Ting JP (1978). Crassulacean Acid Metabolism: Analysis of an Ecological Adaptation. Springer-Verlag, Berlin.

Kores PJ, Molvray M, Weston PH, Hopper SD, et al. (2001). A phylogenetic analysis of Diurideae (Orchidaceae) based on plastid DNA sequence data. Am. J. Bot. 88: 1903-1914.

Kumar S, Tamura K and Nei M (2004). MEGA3: Integrated software for Molecular Evolutionary Genetics Analysis and sequence alignment. Brief. Bioinform. 5: 150-163.

Lüttge U (2004). Ecophysiology of crassulacean acid metabolism (CAM). Ann. Bot. 93: 629-652.

Menezes L (2005). Brazilian Orchids. Available at [http://www.delfinadearaujo.com/generos/cattleya/cat01.htm]. Accessed June 15, 2005.

Molvray M, Kores PJ and Chase MW (1999). Phylogenetic relationships within Korthalsella (Viscaceae) based on nuclear ITS and plastid trnL-F sequence data. Am. J. Bot. 86: 249-260.

Muasya AM, Simpson DA and Chase MW (2002). Phylogenetic relationships in Cyperus L. S.L. (Cyperaceae) inferred from plastid DNA sequence data. Bot. J. Linn. Soc. 138: 145-153.

Nixon KC (2002). WinClada Ver. 1.00.08. Published by the author, Ithaca.

Silva MMP, Vasquez HM, Bressan-Smith RE, Silva JFC, et al. (2001). Varietal differences in the photosynthetic characteristics of Pennisetum purpureum, Schum. Rev. Bras. Zootec. 30: 1975-1983.

Stuntz S and Zotz G (2001). Photosynthesis in vascular epiphytes: a survey of 27 species of diverse taxonomic origin. Flora 196: 132-141.

Taberlet P, Gielly L, Pautou G and Bouvet J (1991). Universal primers for amplification of three non-coding regions of chloroplast DNA. Plant Mol. Biol. 17: 1105-1109.

van den Berg C and Martins PS (1998). Biogeography of Brazilian Cattleyas: Geographic Distribution, Morphological Variability, Evolutionary and Taxonomic Consequences. In: Proceedings of the 15th World Orchid Conference, Rio de Janeiro, 1996. Naturalia Publications, Turriers, 315-320.

van den Berg C, Higgins WE, Dressler RL, Whitten WM, et al. (2000). A phylogenetic analysis of Laeliinae (Orchidae) based on sequence data from internal transcribed spacers (ITS) of nuclear ribosomal DNA. Lindleyana 15: 96-114.

Withner CL (1988). The Cattleyas and their Relatives. I. The Cattleyas. Timber Press, Portland.

Zotz G and Hietz P (2001). The physiological ecology of vascular epiphytes: current knowledge, open questions. J. Exp. Bot. 52: 2067-2078. 